\title{
Taxonomic Notes: A Proposal for Recording the Properties of Putative Taxa of Procaryotes
}

\author{
R. G. E. MURRAY ${ }^{1}$ AND K. H. SCHLEIFER ${ }^{2}$ \\ Department of Microbiology and Immunology, University of Western Ontario, \\ London, Ontario, Canada N6A 5C1, ${ }^{1}$ and Lehrstuhl Mikrobiologie, \\ Technische Universität, D-80290 Munich, Germany ${ }^{2}$
}

\begin{abstract}
The problem that the proposal for recording the properties of putative taxa of procaryotes attempts to redress arises because the International Code of Nomenclature of Bacteria is not able to provide sensible regulation of nomenclature for new taxa defined by very limited data, such as a nucleotide sequence for a small portion of the genome. The constructors of the original code (1957) and the Judicial Commission considering the 1976 and 1990 revisions did not foresee or act upon the possibilities for molecular description and typification of procaryotes that were not yet cultivable. As a result, formal names are being proposed for uncultivated procaryotes whose uniqueness is defined only by very limited characteristics, such as differences in a molecular sequence. As the editors of two journals concerned with the systematics of procaryotes, we recognize that the problem will increase as the available technology gains wider use and becomes easier to apply. Accordingly, this note is presented in advance of discussions by the International Committee on Systematic Bacteriology at the forthcoming congress (July 1994) so that there may be discussions and reaction by colleagues.
\end{abstract}

The phylogenetic approach to systematics and the assessment of taxonomic proposals using nucleic acid hybridization and molecular sequence analysis of semantide macromolecules has been of infinite utility in the phylogenetic reformation of the classification of procaryotic organisms $(12,17)$. Despite this success, it is necessary to apply a broad range of phenotypic and phylogenetic data to the description and taxonomic assignment of novel isolates as recommended by an ad hoc subcommittee of the ICSB (10). This is because the sequences used as phylogenetic data arise from only a small proportion of the genome, and furthermore, phylogenetically related procaryotes can have diverse physiologies whereas physiologically similar organisms can occur in different phylogenetic lineages, as exemplified in the Proteobacteria. The whole capability of the organism must be considered in taxonomic arrangements. Given that an organism can be grown, a range of characteristics can be determined for a phenotypic profile to add to phylogenetic information and to apply to both description and taxonomic assignment.

The problem arises because it is now possible to extract DNA from the environment and identify phylogenetically significant genes of procaryotes (usually $16 \mathrm{~S}$ rRNA genes) that have not yet been cultivated. The corresponding DNA

$\dagger$ This section permits the presentation, in a concise form, of proposals or problems that require the attention of the International Committee on Systematic Bacteriology (ICSB) for formal discussion and informs colleagues internationally so that they may react if they wish to do so. It may also be used as a source of information or to transmit information on approaches, concepts, or arguments arising from outside the pages of the IJSB, which already allows Letters to the Editor concerning publications in that journal. Contributions can be addressed to the Editor or communicated through an officer of the ICSB (see the listing on the title page of every issue) or through the ASM Journals Division as for papers. The contributions should concern matters appropriate to the scientific interests of the ICSB. For example, proposals regarding amendments to the Bacteriological Code should, by statute, be published 3 to 6 months in advance of the ICSB meeting, which is part of the program at IUMS Congresses of Microbiology (Bacteriology Division). fragments are cloned in Escherichia coli to singularize the individual sequences without $(13,16)$ or with prior amplification of these sequences by using the PCR (7). The sequences obtained have to be phylogenetically significant. Therefore, only genes which are ubiquitous, functionally constant, and sufficiently conserved can be used. Moreover, a large data set of sequences of this gene has to be available for comparison. Currently, the 16S rRNA, and to a lesser extent 23S rRNA, elongation factor Tu, and the $\beta$-subunit of ATPase, can be used. Moreover, a major part of the gene has to be sequenced, e.g., at least 1,000 bases from $16 \mathrm{~S}$ rRNA, as recommended by Murray et al. (10). Comparative sequence analysis will reveal whether it is a novel sequence originating from a hitherto unknown organism. In this circumstance, and in the absence of being able to relate this sequence to a known genus, authors have been tempted to propose a new genus and species with less than adequate characterization and rely on the isolated sequence to serve as the type in the sense allowed by Rule 18a of the code. This rule has allowed many species to be named without much supporting data for many years, especially in the case of endosymbionts.

A novel sequence isolated from nature merely indicates that there may be a unique organism in the environment. However, one has to take into consideration that sometimes sequencing and/or amplification errors simulate a novel sequence, suggesting some intraspecies diversity, or that formations of chimeric sequences may be possible (9). Moreover, the possibility that the sequence was retrieved from cell-free (naked) DNA cannot be excluded, and it may have originated from an organism not originally growing in the examined habitat. However, the improved technology of today allows the design of probes complementary to specific regions of the sequence. These probes can be applied and used for the in situ detection and identification of the organism from which the sequence was retrieved $(1-3,5,6$, $14)$. With this approach it is now possible to determine the morphology of the organism and its abundance and distribution in a certain habitat and even to obtain an indication of its growth rate and physiological activity (11). Moreover, by 
TABLE 1. Items for inclusion in the codified record of a provisional taxon

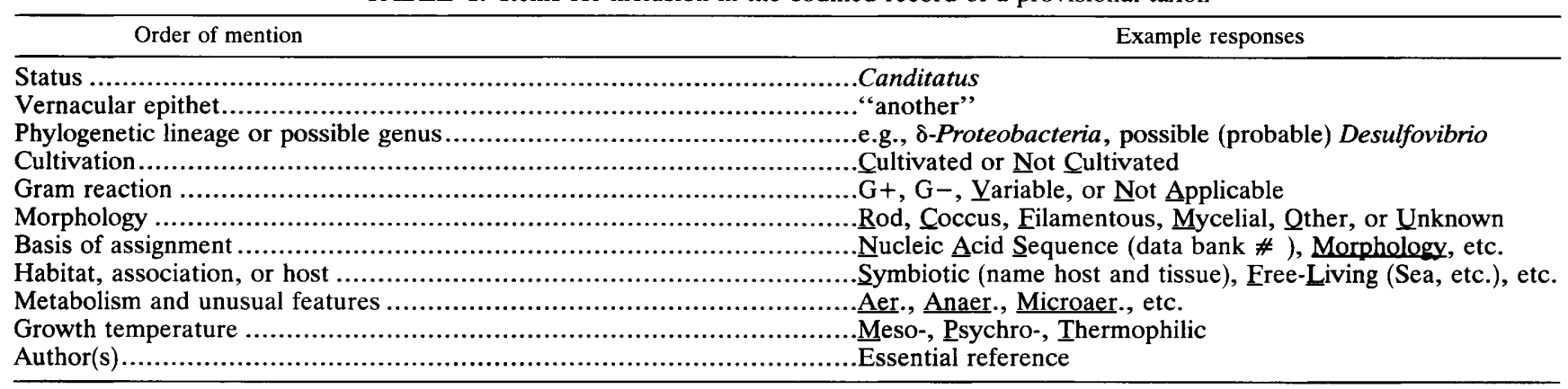

knowing the morphotype it may be possible to assemble further information on the organism by using different staining methods and electron microscopical studies.

If the organism is cultivated and shown to be genotypically distinctive by analysis of the genome (notably by DNA hybridization) or rRNA sequencing, a thorough phenotypic characterization is both possible and needed for an adequate taxonomic description. If the organism is not successfully cultivated, it may be a considerable and arduous research project to find out its requirements for growth and to accomplish a phenotypic description to add to the sequence analysis. In some circumstances, cell-sorting techniques could be applied to preponderant populations (14), or the fractionation of distinctive endosymbionts could be attempted to gain a valid suspension $(6,15)$. The information obtained, even though limited, may be of considerable significance in ecological studies and considerations of biodiversity as well as provide an important lead into future taxonomic groupings. Furthermore, attempts at cultivation should be undertaken and could be based on growth media formulated for the closest culturable relative (8).

The procaryotes of concern are often labelled uncultivable, which is a misleading statement because it is not likely that any of the myriad of them in nature are not cultivable; they grow in nature and we do not know enough about them to provide the appropriate conditions. We need to include their growth physiology and chemotaxonomic characteristics in their description to give flesh to a phylogenetic basic proposal. This does not mean that knowledge of phylogenetically significant sequences in rRNA or genomic DNA is not worthy of record or that the organism in question will not prove to belong to a describable new taxon when more is known about it. The application of specific oligonucleotide probes inferred from the novel sequences allows the identification and detection in situ of a possible novel procaryote despite lack of a culture.

We believe that Rule 18 of the code is not adequate to typification now that molecular data can be used to recognize uniqueness in bacteria that are not yet cultivable. It needs reassessment by the Judicial Commission. In some way the rule must express or respond to a clearer concept of a basic or minimum standard for the description of any new procaryotic taxon.

Some procaryotes that are difficult to grow or are not yet cultivable may be shown by molecular genetic methods to belong within an established taxon, and these are capable of either formal or informal assignment, depending on the level of characterization attained. They are not a problem in our context, and if the description is deferred, they can be placed as genomospecies in the genus. However, even when they are cultivable and genotypically but not phenotypically distinct from an established species (e.g., see reference 4), this category, genomospecies, should be considered by the ICSB at this time as another helpful candidate status.

We believe that it would be helpful to have a category or rank to provide a proper record of sequence-based potential new taxa at the genus level, and, associated with this, a data bank should be developed to provide for storage, search, and retrieval of the data. To that end, we propose the category Candidatus (L. candidatus, a candidate, to indicate that the assignment is provisional) followed by a descriptive vernacular epithet and then the available essential information (e.g., see Table 1).

The information needed to fulfill the intention of the designation Candidatus must include both the sequence and the identification of a morphotype with a specific probe inferred from a characteristic sequence. The assignment to Candidatus would be valid upon acceptance by the appropriate data bank. The data bank may not be the same as that employed for, say, nucleic acid sequences; the sequences should be recorded in both places in that case. It would be for the ICSB to decide whether or not these provisional names should appear in a separate listing in IJSB.

An example, using data derived from a recent publication and with abbreviations from Table 1 , would be as follows:

"Candidatus intracellularis" [( $\delta$-Proteobacteria $) \mathrm{NC}$; G-R; NAS (GenBank \# L 15739), oligonucleotide sequence complementary to unique region of $16 \mathrm{~S}$ rRNA 5'-GTCTTGAGGCTCCCCGAAAGGCACCTC TTAATC-3', S (Sus, ileum); M;] Gebhart et al. Int. J. Syst. Bacteriol. 43:533, 1993].'

A brief form of this for first mention in the text of a paper could be "Candidatus ( $\delta$-Proteobacteria) intracellularis," Gebhart et al., 1993. Because this designation does not qualify as a valid name under the code, it should be printed within quotation marks.

When more information is available it is possible that a provisional genus name could be given, even though it would have no legitimacy under the code and, when used, should be written within inverted commas as for all other candidate taxa. This could be considered if the bacterium identified in situ reveals unique properties, morphology, physiology, or habitat. An example from the current literature would be as follows:

"Candidatus magnetobacterium" [(new subclass of Proteobacteria or new lineage) NC; G-R; NAS (EMBL X71838), oligonucleotide sequence complementary to unique region of 16S rRNA 5'-GCCATCC CCTCGCTTACT-3', FL (freshwater lake sediment), 
microaer., magnetosomes, sulfur inclusion, M. "Candidatus Magnetobacterium bavaricum" Spring et al., Appl. Environ. Microbiol. 59:2397, 1993.]

Further research may provide sufficient data for a satisfactory description and a formal name that can be validly published. When this occurs, the Candidatus entry should be deleted; deletion should also occur if an item is found to be a mistake. The work of the discoverer(s) should not be lost when a formal name is assigned and should be included in the ascription. It must be hoped that the candidate names used could be validated, but this cannot be guaranteed, and other names might then be more appropriate.

Proposals to the ICSB.

The Judicial Commission should consider whether or not Rule 18 of the Bacteriological Code is an adequate regulation concerning the type for a procaryote that is not cultivable and, particularly, when the description is based upon molecular sequence data.

The Judicial Commission should consider whether or not it is possible to devise and publish a minimum standard or guideline for the description of a procaryote.

The ICSB should devise and put into operation a codified record of an uncultivated procaryote that nucleotide sequence analysis and identification of a morphotype indicate belong to a new taxon at the rank of genus but whose description is otherwise inadequate for formal naming.

To indicate provisional status for such a bacterium, let it be given an appropriate trivial or vernacular name assigned to the rank or category of Candidatus, which can be considered equivalent to genus.

The data bank should store the codified record of salient features and the source derived from the original publication together with the sequence data essential to recognition and the reference. The author(s) should be responsible for submission.

The intent is both storage and retrieval for comparative purposes.

Provision should be made for recognition of the discoverer(s) when further work makes it possible to give a formal name. The ascription for a formal name when it becomes possible should include the discoverer(s) noted in brackets after the name and before the authors of the name if they are not the same.

A cultivable strain aligned genotypically to a genus and that cannot be distinguished phenotypically from an existent species should be accorded candidate status when the data support such a distinction, e.g., as a genomospecies.

We are indebted to authors of papers that exemplify the problem we have identified and with whom we have had extensive correspondence or discussion. We are also indebted to our Associate Editors, some referees for our journals (IJSB and Systematic and Applied Microbiology), and the Board of Trustees of Bergey's Manual, who have taken part in discussions and correspondence on the subject.

\section{REFERENCES}

1. Amann, R. I., L. Krumholz, and D. A. Stahl. 1990. Fluorescent oligonucleotide probing of whole cells for determinative, phylogenetic, and environmental studies in microbiology. J. Bacteriol. 172:762-770.
2. Amann, R. I., N. Springer, W. Ludwig, H. D. Görtz, and K. H. Schleifer. 1991. Identification in situ detection/identification and phylogeny of uncultured bacterial endosymbionts. Nature (London) 351:161-164.

3. Angert, E. R., K. D. Clements, and N. R. Pace. 1993. The largest bacterium. Nature (London) 362:239-241.

4. Brenner, D. J., D. G. Hollis, C. W. Moss, C. K. English, G. S. Hall, J. Vincent, J. Radosevic, K. A. Birkness, W. F. Bibb, F. D. Quinn, B. Swaminathan, R. E. Weaver, M. W. Reeves, S. P. O'Connor, P. S. Hayes, F. C. Tenover, A. G. Steigerwalt, B. A. Perkins, M. I. Daneshvar, B. C. Hill, J. A. Washington, T. C. Woods, S. B. Hunter, T. L. Hadfield, G. W. Ajello, A. F. Kaufmann, D. J. Wear, and J. D. Wenger. 1991. Proposal of Afipia gen. nov., with Afipia felis sp. nov. (formerly the cat scratch disease bacillus), Afipia clevelandensis sp. nov. (formerly the Cleveland Clinic Foundation strain), Afipia broomeae sp. nov., and three unnamed genospecies. J. Clin. Microbiol. 29: $2450-2460$

5. DeLong, E. F., G. S. Wickham, and N. R. Pace. 1989. Phylogenetic stains: ribosomal RNA-based probes for the identification of single cells. Science 243:1360-1363.

6. Gebhart, C. J., S. M. Barns, S. McOrist, G. F. Lin, and G. H. K. Lawson. 1993. Ileal symbiont intracellularis, an obligate intracellular bacterium of porcine intestines showing a relationship to Desulfovibrio species. Int. J. Syst. Bacteriol. 43:535-538.

7. Giovannoni, S. J., T. B. Britschgi, C. L. Moyer, and K. G. Field. 1990. Genetic diversity in Sargasso Sea bacterioplankton. Nature (London) 345:60-63.

8. Kane, M. D., L. K. Poulsen, and D. A. Stahl. 1993. Monitoring the enrichment and isolation of sulfate-reducing bacteria by using oligonucleotide hybridization probes designed from environmentally derived $16 \mathrm{~S}$ rRNA sequences. Appl. Environ. Microbiol. 59:682-686.

9. Liesack, W., H. Weyland, and E. Stackebrandt. 1991. Potential risks of gene amplification by PCR as determined by $16 \mathrm{~S}$ rDNA analysis of mixed-culture of strict barophilic bacteria. Microb. Ecol. 21:191-198.

10. Murray, R. G. E., D. J. Brenner, R. R. Colwell, P. de Vos, M. Goodfellow, P. A. D. Grimont, N. Pfennig, E. Stackebrandt, and G. A. Zavarzin. 1990. Report of the ad hoc Committee on Approaches to Taxonomy within the Proteobacteria. Int. J. Syst. Bacteriol. 40:213-215.

11. Poulsen, L. K., G. Ballard, and D. A. Stahl. 1993. Use of rRNA fluorescence in situ hybridization for measuring the activity of single cells in young and established biofilms. Appl. Environ. Microbiol. 59:1354-1360.

12. Schleifer, K. H., and W. Ludwig. 1989. Phylogenetic relationships among bacteria, p. 103-117. In B. Fernholm, K. Brenner, and $H$. Jörnvall (ed.), Hierachy of life. Excerpta Medica, Amsterdam.

13. Schmidt, T. M., E. F. DeLong, and N. R. Pace. 1991. Analysis of a marine picoplankton community by $16 \mathrm{~S}$ rRNA gene cloning and sequencing. J. Bacteriol. 173:4371-4378.

14. Spring, S., R. I. Amann, W. Ludwig, K. H. Schleifer, H. van Gemerden, and N. Petersen. 1993. Dominating role of an unusual magnetotactic bacterium in the microaerobic zone of a freshwater sediment. Appl. Environ. Microbiol. 59:2397-2403.

15. Springer, N., W. Ludwig, W. Drozanski, R. I. Amann, and K. H. Schleifer. 1992. The phylogenetic status of Sarcobium lyticum, an obligate intracellular bacterial parasite of small amoeba. FEMS Microbiol. Lett. 96:199-202.

16. Ward, D. M., R. Weller, and M. M. Bateson. 1990. 16S rRNA sequences reveal numerous uncultured microorganisms in a natural community. Nature (London) 345:63-65.

17. Woese, C. R. 1987. Bacterial evolution. Microbiol. Rev. 51:221271. 